\section{Nutritional status of adolescents: the 11-year follow-up of the 1993 Pelotas (Brazil) birth cohort study}

\author{
Estado nutricional de adolescentes: a visita de 11 \\ anos da coorte de nascimentos de Pelotas, Rio \\ Grande do Sul, Brasil, 1993
}

\author{
${ }^{1}$ Faculdade de Nutrição, \\ Universidade Federal de \\ Pelotas, Pelotas, Brasil. \\ 2 Programa de Pós- \\ graduação em Epidemiologia, \\ Universidade Federal de \\ Pelotas, Pelotas, Brasil. \\ 3 Programa de Pós-graduação \\ em Educação Física, \\ Universidade Federal de \\ Pelotas, Pelotas, Brasil. \\ Correspondence \\ C. L. Araújo \\ Departamento de Nutrição, \\ Faculdade de Nutrição \\ Universidade Federal de \\ Pelotas. \\ Campus Universitário $s / n$, \\ Pelotas, RS \\ 96001-970, Brasil. \\ cora.araujo@terra.com.br
}

\begin{abstract}
We evaluate the influence of demographic, socioeconomic, and maternal variables on the nutritional status of adolescents aged 11 years. We conducted a prospective cohort study including 4,452 adolescents born in Pelotas, Southern Brazil, in 1993, accounting for $87.5 \%$ of the original cohort. Nutritional status was evaluated based on World Health Organization criteria. Subjects were clas sified according to nutritional status into thin, normal, overweight and obese. Independent variables analyzed included skin color, socioeconomic status, maternal schooling, and maternal body mass index (BMI). Analyses were stratified by sex, and multivariable regression was performed using the multinomial logistic approach. Overall, 7\% of adolescents were classified as thin, 11.6\% as overweight, and $11.6 \%$ as obese. Among boys, thinness was inversely associated with maternal schooling and maternal BMI. Among girls, thinness was directly associated with maternal BMI. Overweight and obesity were directly associated with socioeconomic status and maternal BMI, the former showing the strongest association with nutritional status among adolescents.
\end{abstract}

Nutritional Status; Adolescent; Cohort Studies
Cora Luiza Araújo 1,2

Samuel C. Dumith 2

Ana M. B. Menezes 2

Pedro C. Hallal 2,3

Maria de Fátima A. Vieira 1,2

Samanta W. Madruga 2

Cesar G. Victora ${ }^{2}$

\section{Introduction}

Associations between diet, nutrition, and chronic diseases are well documented 1,2,3. The 2002 World Health Organization (WHO) report on world health indicate that undernutrition, along with micronutrient deficits, is responsible for over half the indirect cost of disease in lowincome countries ${ }^{4}$. The global effort towards eradication of underweight has been successful in most countries. However, the health policies and nutritional interventions involved in this effort may be contributing to a rapid increase in overweight among all age groups 5,6.

Improving the targeting of nutritional interventions will require greater understanding of the dynamics of the coexistence of undernutrition and obesity. Prevalence of undernutrition is falling in much of the world, whereas overweight prevalence has been increasing rapidly in recent decades in several countries, including Brazil $7,8,9$. Our current and future challenge in terms of nutrition policy is to eradicate underweight associated with insufficient calorie intake and prevent micronutrient deficit without leading to a concomitant increase in prevalence of overweight and obesity 6,7.

Previous studies provide evidence of an association between diet, physical activity, ethnicity, birthweight, nutritional status of parents, maternal schooling, and the family's socioeconomic level, among others, and occurrence of undernu- 
trition and overweight among preschoolers 7,10. Studies of adolescent subjects focus primarily on overweight, and come mostly from developed countries 3 .

The aim of the present study was to investigate the association between demographic, socioeconomic, and maternal factors and undernutrition or overweight in a cohort of 11-year old adolescents from Southern Brazil.

\section{Methods}

The subjects of the present study $(\mathrm{N}=4,452)$ are part of a prospective cohort that included all hospital births taken place in 1993 in the city of Pelotas, state of Rio Grande do Sul, in Southern Brazil. While still in the hospital, a questionnaire was administered to mothers, and newborns were weighed and measured. Subsamples of these children were visited at 1,3 , and 6 months, and 1, 4, 6, and 9 years of age. In 2004-2005, we attempted to locate all members of this cohort for a further follow-up, the details of which are described elsewhere ${ }^{11}$. Here, we present the results of this latest visit, when adolescents were 11 years old on average.

We studied as an outcome the adolescent's nutritional status, with subjects being classified into four groups: thin, normal, overweight, and obese 12 . We regarded as thin adolescents whose body mass index (BMI) was below percentile 5 (P5) for the subject's sex and age. Adolescents with $\mathrm{BMI} \geq \mathrm{P} 85$ and subscapular and tricipital skinfold measurements $\geq$ P90 specific for their sex and age were classified as obese. Those with BMI $\geq$ P85 and at least one skinfold below P90 were classified into the risk category for overweight (from now on referred to simply as "overweight").

Skinfolds were measured using a Cescorf scientific caliper (Porto Alegre, Brazil), following the recommendations of Lohman 13. BMI was calculated using weight and height measures obtained by the study team using a SECA digital scale (Birmingham, UK) with $100 \mathrm{~g}$ precision and a portable aluminum stadiometer with $1 \mathrm{~mm}$ precision.

Interviewers underwent standardization testing prior to beginning fieldwork to determine the repeatability and validity of measurements. Acceptable technical measurement errors (TME) were defined according to the recommendations of Cameron 14. Thus, acceptable intra-observer TMEs were $1.17 \mathrm{~kg}, 0.49 \mathrm{~cm}, 0.80 \mathrm{~mm}$, and $1.83 \mathrm{~mm}$ for measures of weight, height, and tricipital and subscapular skinfolds, respectively. Interobserver TMEs considered as acceptable were
$1.23 \mathrm{~kg}, 0.68 \mathrm{~cm}, 1.89 \mathrm{~mm}$, and $1.53 \mathrm{~mm}$ for these same measures. Throughout the duration of data collection, which lasted for eight months, interviewers were re-standardized every two months for anthropometric measurement and evaluated with respect to questionnaire administration.

Independent variables studied included demographic (self-ascribed skin color: white, black/mixed/others), socioeconomic (assets index in quintiles and mother's schooling in years $(0-4,5-8,9-11$, and $\geq 12)$ and maternal (BMI in $\mathrm{kg} / \mathrm{m}^{2}$ : < 18.5; 18.5-24.9; 25.0-29.9; $\geq 30$ ) factors, all of which were obtained during the 11-year follow-up. The assets index was constructed using principal component analysis, based on a list of 18 socioeconomic indicators. These variables were hierarchized according to an analysis model for confounder control. Demographic and socioeconomic factors were placed in the first level, whereas maternal BMI was placed more proximal to the outcome. Each variable was adjusted for variables in the same or higher levels.

Results are presented separately for boys and girls. We describe the distribution of the outcome according to categories of each studied variable. Since the outcome measure has four categories, we used multinomial logistic regression 15 for both crude and adjusted analyses. This statistical approach calculates the probability of a subject falling into a given risk category (thin, overweight, or obese) in comparison to the reference group (normal). We used the Wald test for heterogeneity and the linear trend test for dichotomous or nominal variables and ordinal categorical variables, respectively. Statistical significance was set at $5 \%$, and analyses were carried out using Stata 9.2 software (Stata Corp., Colege Station, USA).

The study protocol was submitted to and approved by the Research Ethics Committee of the Federal University in Pelotas.

\section{Results}

The distribution of adolescents according to nutritional status showed that $69 \%$ of subjects were normal, $7 \%$ were underweight, and $23 \%$ had excess weight (overweight or obesity). Prevalence of overweight was slightly higher among girls ( $13 \%$, vs. $12.1 \%$ among boys; $p=0.002$ ), whereas boys had an almost twofold higher prevalence of obesity ( $15.1 \%$ vs. $8.4 \%$ among girls; $\mathrm{p}<0.001$ ). Differences between sexes were not statistically significant in the thin and normal categories. The distribution of nutritional status according to independent variables is shown in Tables 1 (boys) and 2 (girls). 
Description of nutritional status among boys, according to dependent variables. 1993 Pelotas (Brazil) birth cohort study, 20042005 follow-up.

\begin{tabular}{|c|c|c|c|c|c|}
\hline Variable & $\mathbf{n}$ & Thin (\%) & Normal (\%) & Overweight (\%) & Obese (\%) \\
\hline \multicolumn{6}{|l|}{ Skin color } \\
\hline White & 1,481 & 5.6 & 67.0 & 11.4 & 16.1 \\
\hline Black/Mixed & 587 & 8.7 & 72.9 & 6.1 & 12.3 \\
\hline \multicolumn{6}{|c|}{ Assets index (quintile) } \\
\hline 1st (lowest) & 445 & 8.6 & 76.4 & 6.3 & 8.8 \\
\hline $2^{\text {nd }}$ & 414 & 8.2 & 74.2 & 8.5 & 9.2 \\
\hline 3 rd & 400 & 8.3 & 67.9 & 8.0 & 15.8 \\
\hline 4 th & 415 & 4.8 & 64.3 & 11.8 & 19.1 \\
\hline $5^{\text {th }}$ & 437 & 3.2 & 56.2 & 16.7 & 23.9 \\
\hline \multicolumn{6}{|c|}{ Maternal schooling (years) } \\
\hline $0-4$ & 567 & 8.7 & 73.7 & 8.1 & 9.5 \\
\hline $5-8$ & 922 & 7.0 & 69.3 & 8.5 & 15.3 \\
\hline $9-11$ & 475 & 4.4 & 64.8 & 12.0 & 18.7 \\
\hline$\geq 12$ & 210 & 2.4 & 58.7 & 17.6 & 21.4 \\
\hline \multicolumn{6}{|c|}{ Maternal BMI $\left(\mathrm{kg} / \mathrm{m}^{2}\right)$} \\
\hline$\leq 18.5$ & 36 & 25.0 & 66.7 & 5.6 & 2.8 \\
\hline $18.5-24.9$ & 857 & 8.7 & 73.4 & 7.7 & 10.2 \\
\hline $25.0-29.9$ & 671 & 4.3 & 67.6 & 10.8 & 17.3 \\
\hline$\geq 30.0$ & 470 & 2.8 & 60.9 & 13.4 & 23.0 \\
\hline Total & 2,192 & 6.4 & 68.5 & 10.1 & 15.1 \\
\hline
\end{tabular}

BMI: body mass index.

Boys (Table 3) of black or mixed skin color were less likely to be overweight than those with white skin, even after adjustment for socioeconomic factors $(p=0.046)$. Skin color was associated with a non-significant increase $(\mathrm{p}=0.08 \mathrm{af}-$ ter adjustment) in thinness. The assets index was positively associated only with overweight and obesity ( $\mathrm{p}<0.001$ ), whereas maternal schooling was negatively associated with the probability of being thin $(\mathrm{p}=0.049)$. Maternal BMI was associated negatively with thinness $(p<0.001)$, and positively with overweight and obesity ( $\mathrm{p}=$ $0.001)$.

Among girls, skin color and maternal schooling showed no association with nutritional status (Table 4). The assets index was positively associated only with obesity $(\mathrm{p}=0.042)$. As for boys, maternal BMI was negatively associated with thinness also among girls $(\mathrm{p}<0.001)$. Associations among girls were stronger than among boys.

\section{Discussion}

Our present results confirm recent findings on the nutritional status of children, adolescents, and adults from most middle-income countries and some low-income countries, namely that prevalence of excess weight exceeds that of thinness. Our data also indicate the extent to which demographic, socioeconomic, and maternal status can influence the occurrence of thinness, overweight, and obesity already in early adolescence. Moreover, we also show that such effects differ between boys and girls.

An important aspect of the present study its reliance on not only weight and height, but also on tricipital and subscapular skinfold measurements to classify the nutritional status of youths. The combination of BMI and high skinfold values increases the likelihood of correctly identifying adolescents that have not only high BMI, but also excess body fat 12. A limitation of this study, on the other hand, is the absence of an objective measure of pubertal status, since our interviews were carried out at the subject's home rather than in clinical settings. However, the fraction of adolescents that have entered puberty at age 11 is relatively low 16 . In the studied cohort, about $17 \%$ of girls were postmenarcheal at the time of the 11-years follow-up.

The finding that, among boys, prevalence of obesity (15\%) was higher than that of overweight $(10 \%)$ is worthy of note. Among girls, 
Description of nutritional status among girls, according to dependent variables. 1993 Pelotas (Brazil) birth cohort study, 20042005 follow-up.

\begin{tabular}{|c|c|c|c|c|c|}
\hline Variable & $\mathrm{n}$ & Thin (\%) & Normal (\%) & Overweight (\%) & Obese (\%) \\
\hline \multicolumn{6}{|l|}{ Skin color } \\
\hline White & 1,472 & 7.8 & 70.2 & 13.3 & 8.7 \\
\hline Black/Mixed & 672 & 7.0 & 72.3 & 12.8 & 7.9 \\
\hline \multicolumn{6}{|c|}{ Assets index (quintile) } \\
\hline 1st (lowest) & 418 & 7.9 & 74.6 & 12.0 & 5.5 \\
\hline $2^{\text {nd }}$ & 437 & 7.8 & 71.9 & 14.2 & 6.2 \\
\hline $3 r d$ & 457 & 9.2 & 70.8 & 10.8 & 9.2 \\
\hline 4 th & 442 & 6.6 & 67.4 & 14.3 & 11.8 \\
\hline $5^{\text {th }}$ & 419 & 7.7 & 68.3 & 15.1 & 8.9 \\
\hline \multicolumn{6}{|c|}{ Maternal schooling (years) } \\
\hline $0-4$ & 578 & 6.4 & 74.1 & 12.3 & 7.3 \\
\hline $5-8$ & 979 & 8.6 & 71.0 & 12.8 & 7.6 \\
\hline $9-11$ & 472 & 7.6 & 68.4 & 13.8 & 10.2 \\
\hline$\geq 12$ & 211 & 7.7 & 68.4 & 13.9 & 10.1 \\
\hline \multicolumn{6}{|c|}{ Maternal BMI (kg/m²) } \\
\hline$\leq 18.5$ & 33 & 39.4 & 51.5 & 6.1 & 3.0 \\
\hline $18.5-24.9$ & 870 & 12.1 & 73.9 & 9.8 & 4.3 \\
\hline $25.0-29.9$ & 739 & 4.3 & 74.2 & 13.3 & 8.1 \\
\hline$\geq 30.0$ & 465 & 3.9 & 60.3 & 19.6 & 16.2 \\
\hline Total & 2,260 & 7.7 & 71.1 & 13.0 & 8.2 \\
\hline
\end{tabular}

BMI: body mass index.

prevalence of overweight (13\%) was higher than that of obesity ( $8 \%)$, as is normally the case ${ }^{8}$. In the 2006 National Survey of Demography and Health (PNDS-2006) adolescents aged 15-19 years showed higher prevalence of overweight (17.2\%), and lower prevalence of obesity (4.4\%), than those in the present study. In other words, adolescents in the 1993 Pelotas birth cohort were at higher risk in terms of obesity when compared to the nationwide sample.

In recent years, only a few studies have measured the prevalence of, and investigated risk factors for, underweight among adolescents, possibly because this is an infrequent phenomenon in high-income countries, where most studies are conducted. Linear deficit, however, is still extremely common among children from poor countries 17 , and persists, albeit at lower frequency, in middle-income countries 7 . In the present study, as recommended, we used P5 to classify subjects as thin. Prevalence of thinness was slightly higher than the $5 \%$ that would be expected when using P5 as a cutoff: $6.4 \%$ among boys and $7.7 \%$ among girls. This result is compatible with the good level of food security enjoyed by Brazil's Southern Region, but should not be extrapolated to the country as a whole 18 .
Both thinness and excess weight are matters of concern. This is especially true during adolescence, when roughly $15 \%$ of adult height and $50 \%$ of adult weight is gained ${ }^{19}$. Adolescence is thus a phase of intense growth, which demands an intake of nutrients that is sufficient to satisfy the body's nutritional needs without causing excessive weight gain.

Thinness, overweight, and obesity were distributed differently among boys and girls. Whereas prevalence of overweight at age 11 years was higher in girls, obesity at this age was more frequent among boys. Kelishadi 8, in a review study, shows that there is a constant pattern in the distribution of overweight and obesity among boys and girls living in middle and low-income countries. Only one of the thirty studies reviewed by Kelishadi 8 - carried out in Kuwait - showed a trend similar to that reported in the present study, that is, girls showed greater prevalence of overweight, and boys of obesity. Results similar to ours were also reported for North-American children aged 6-11 years in the 2003-2004 National Health and Nutrition Examination Survey (NHANES) 20, where prevalence of overweight was higher among girls than among boys (38\% vs. $36.5 \%$, respectively). This trend was inverted 
Crude and adjustment associations with nutritional status among boys, according to independent variables *. 1993 Pelotas (Brazil) birth cohort study, $2004-$ 2005 follow-up.

\begin{tabular}{|c|c|c|c|c|c|c|}
\hline \multirow[t]{2}{*}{ Variable } & \multicolumn{2}{|c|}{ Thin } & \multicolumn{2}{|c|}{ Overweight } & \multicolumn{2}{|c|}{ Obese } \\
\hline & OR $_{\text {crude }}(95 \% \mathrm{Cl})$ & $\mathrm{OR}_{\text {adjusted }}(95 \% \mathrm{Cl})$ & $\mathrm{OR}_{\text {crude }}(95 \% \mathrm{Cl})$ & $\mathrm{OR}_{\text {adjusted }}(95 \% \mathrm{Cl})$ & OR $_{\text {crude }}(95 \% \mathrm{Cl})$ & $\mathrm{OR}_{\text {adjusted }}(95 \% \mathrm{Cl})$ \\
\hline Skin color & $p=0.059$ & $p=0.082$ & $p<0.001$ & $p=0.046$ & $p=0.017$ & $p=0.773$ \\
\hline White & 1.00 & 1.00 & 1.00 & 1.00 & 1.00 & 1.00 \\
\hline Black/Mixed & $1.42(0.99 ; 2.06)$ & $1.40(0.96 ; 2.04)$ & $0.50(0.34 ; 0.72)$ & $0.67(0.45 ; 0.99)$ & $0.70(0.53 ; 0.94)$ & $0.96(0.70 ; 1.30)$ \\
\hline Assets index (quintile) & $p=0.017 * \star$ & $p=0.667 * \star$ & $p<0.001$ ** & $p<0.001$ ** & $p<0.001$ ** & $p<0.001 * \star$ \\
\hline 1st (lowest) & 1.00 & 1.00 & 1.00 & 1.00 & 1.00 & 1.00 \\
\hline $2^{\text {nd }}$ & $0.99(0.61 ; 1.61)$ & $1.10(0.66 ; 1.82)$ & $1.38(0.82 ; 2.32)$ & $1.37(0.80 ; 2.33)$ & $1.08(0.67 ; 1.73)$ & $1.04(0.64 ; 1.67)$ \\
\hline $3 r d$ & $1.09(0.66 ; 1.78)$ & $1.31(0.77 ; 2.23)$ & $1.43(0.84 ; 2.43)$ & $1.43(0.83 ; 2.49)$ & $2.02(1.31 ; 3.11)$ & $1.88(1.21 ; 2.91)$ \\
\hline 4 th & $0.67(0.38 ; 1.18)$ & $0.84(0.45 ; 1.56)$ & $2.23(1.36 ; 2.65)$ & $2.12(1.24 ; 3.64)$ & $2.58(1.70 ; 3.91)$ & $2.40(1.55 ; 3.71)$ \\
\hline 5 th & $0.51(0.27 ; 1.96)$ & $0.84(0.37 ; 1.89)$ & $3.61(2.26 ; 5.75)$ & $3.06(1.71 ; 5.47)$ & $3.69(2.47 ; 5.52)$ & $3.52(2.19 ; 5.66)$ \\
\hline Maternal schooling (years) & $p=0.004 * \star$ & $p=0.049 * \star$ & $p<0.001 * \star$ & $p=0.450 \star \star$ & $\mathrm{p}<0.001^{\star \star}$ & $p=0.614 * \star$ \\
\hline $0-4$ & 1.00 & 1.00 & 1.00 & 1.00 & 1.00 & 1.00 \\
\hline $5-8$ & $0.86(0.58 ; 1.27)$ & $0.85(0.56 ; 1.31)$ & $1.11(0.76 ; 1.63)$ & $0.93(0.61 ; 1.40)$ & $1.70(2.21 ; 2.38)$ & $1.27(0.89 ; 1.81)$ \\
\hline $9-11$ & $0.58(0.34 ; 0.99)$ & $0.59(0.32 ; 1.06)$ & $1.68(1.11 ; 2.54)$ & $1.04(0.65 ; 1.67)$ & $2.23(1.54 ; 3.23)$ & $1.24(0.81 ; 1.89)$ \\
\hline$\geq 12$ & $0.35(0.14 ; 0.89)$ & $0.43(0.13 ; 1.39)$ & $2.73(1.69 ; 4.40)$ & $1.23(0.67 ; 2.25)$ & $2.83(1.81 ; 4.40)$ & $1.15(0.69 ; 1.94)$ \\
\hline Maternal BMI $\left(\mathrm{kg} / \mathrm{m}^{2}\right)$ & $p<0.001 * \star$ & $p<0.001 * *$ & $p<0.001 * \star$ & $p<0.001 * \star$ & $p<0.001 * \star$ & $p<0.001 * \star$ \\
\hline$\leq 18.5$ & $3.17(1.42 ; 7.08)$ & $3.01(1.26 ; 7.20)$ & $0.79(0.18 ; 3.42)$ & $1.01(0.24 ; 4.34)$ & $0.30(0.04 ; 2.25)$ & $0.41(0.05 ; 3.08)$ \\
\hline $18.5-24.9$ & 1.00 & 1.00 & 1.00 & 1.00 & 1.00 & 1.00 \\
\hline $25.0-29.9$ & $0.54(0.35 ; 0.85)$ & $0.52(0.33 ; 0.81)$ & $1.51(1.06 ; 2.15)$ & $1.59(1.10 ; 2.30)$ & $1.84(1.36 ; 2.50)$ & $1.82(1.36 ; 2.55)$ \\
\hline$\geq 30.0$ & $0.39(0.21 ; 0.71)$ & $0.32(0.17 ; 0.59)$ & $2.09(1.44 ; 3.03)$ & $2.65(1.78 ; 3.94)$ & $2.72(1.98 ; 3.72)$ & $3.41(2.45 ; 4.75)$ \\
\hline
\end{tabular}

OR: odds ratio; $95 \% \mathrm{Cl}$ : $95 \%$ confidence interval; BMI: body mass index.

* The "normal" group is the reference category for nutritional status;

** $\mathrm{p}$-value for linear trend.

with respect to obesity, the prevalence of which was higher among boys than among girls (19.9\% and $17.6 \%$ respectivley). In the 2002-2003 Brazilian Household Budget survey (POF) 21, prevalence of obesity among Southern Brazilian boys (3.1\%) was slightly higher than among girls from the same region $(2.9 \%)$, whereas girls were more frequently overweight ( $15.6 \%$ vs. $13.6 \%$ for boys). Higher prevalence of overweight among girls, and of obesity among boys, may reflect a new trend in excess weight patterns among young adolescents.

There are virtually no recent studies evaluating the association between thinness and sex, skin color, race, mother's schooling, or family socioeconomic status among adolescents from middle and low-income countries 22 . In the present analysis, thinness was found to be significantly associated with only two variables: its prevalence was lower among boys born to mothers with greater schooling, and higher among mothers with low BMI. Boys with black or mixed skin showed higher prevalence of thinness than those with white skin, but this difference lost sta- tistical significance after adjustment for socioeconomic variables.

Several studies have reported associations between excess weight and skin color or ethnicity. A review by Kumanyika 10 showed that fast-food consumption was higher among black NorthAmerican girls than among their white counterparts. Data from the 2003-2004 NHANES 20 show that Mexican-American and non-Hispanic black children were at higher risk of obesity than white non-Hispanics. In the Pelotas cohort, white boys showed higher risk of overweight, but not of obesity, when compared to those with black/mixed skin. No such association was detected among girls. It is possible that, as the process of nutritional transition continues, the Brazilian pattern will become more similar to that of the United States.

Income, parental schooling, and other indicators of socioeconomic status have been widely studied with respect to their effects on prevalence of overweight and obesity. In rich countries, trends among adolescents are not clear, and tend to vary according to sex. A study carried 
Table 4

Crude and adjustment associations with nutritional status among girls, according to independent variables *. 1993 Pelotas (Brazil) birth cohort study, 20042005 follow-up.

\begin{tabular}{|c|c|c|c|c|c|c|}
\hline \multirow[t]{2}{*}{ Variable } & \multicolumn{2}{|c|}{ Thin } & \multicolumn{2}{|c|}{ Overweight } & \multicolumn{2}{|c|}{ Obese } \\
\hline & $\mathrm{OR}_{\text {crude }}(95 \% \mathrm{Cl})$ & $\mathrm{OR}_{\text {adjusted }}(95 \% \mathrm{Cl})$ & OR $_{\text {crude }}(95 \% \mathrm{Cl})$ & $\mathrm{OR}_{\text {adjusted }}(95 \% \mathrm{Cl})$ & OR $_{\text {crude }}(95 \% \mathrm{Cl})$ & $\mathrm{OR}_{\text {adjusted }}(95 \% \mathrm{Cl})$ \\
\hline Skin color & $p=0.461$ & $p=0.483$ & $p=0.610$ & $p=0.988$ & $p=0.452$ & $p=0.732$ \\
\hline White & 1.00 & 1.00 & 1.00 & 1.00 & 1.00 & 1.00 \\
\hline Black/Mixed & $0.88(0.61 ; 1.25)$ & $0.87(0.60 ; 1.27)$ & $0.93(0.71 ; 1.23)$ & $1.00(0.75 ; 1.35)$ & $0.88(0.63 ; 1.23)$ & $0.94(0.65 ; 1.35)$ \\
\hline Assets index (quintile) & $p=0.958 * \star$ & $p=0.685 * \star$ & $p=0.121 \star \star$ & $p=0.267 \star \star$ & $p=0.001 \star \star$ & $p=0.042 * \star$ \\
\hline 1st (lowest) & 1.00 & 1.00 & 1.00 & 1.00 & 1.00 & 1.00 \\
\hline $2^{\text {nd }}$ & $1.02(0.62 ; 1.70)$ & $0.98(0.58 ; 1.65)$ & $1.23(0.82 ; 1.85)$ & $1.20(0.80 ; 1.80)$ & $1.17(0.65 ; 2.08)$ & $1.12(0.62 ; 2.00)$ \\
\hline $3 r d$ & $1.23(0.76 ; 1.99)$ & $1.12(0.68 ; 1.86)$ & $0.95(0.62 ; 1.45)$ & $0.95(0.62 ; 1.45)$ & $2.76(1.04 ; 3.00)$ & $1.66(0.95 ; 2.89)$ \\
\hline $4^{\text {th }}$ & $0.92(0.55 ; 1.55)$ & $0.84(0.48 ; 1.46)$ & $1.32(0.88 ; 1.98)$ & $1.29(0.84 ; 1.97)$ & $2.37(1.41 ; 3.97)$ & $2.10(1.22 ; 3.62)$ \\
\hline $5^{\text {th }}$ & $1.07(0.64 ; 1.78)$ & $0.94(0.50 ; 1.74)$ & $1.38(1.92 ; 2.08)$ & $1.35(1.84 ; 2.18)$ & $1.77(1.03 ; 3.05)$ & $1.33(0.68 ; 2.58)$ \\
\hline Maternal schooling (years) & $p=0.346 * \star$ & $p=0.390 * \star$ & $p=0.258 * \star$ & $p=0.965 * \star$ & $p=0.040 * \star$ & $p=0.206 * \star$ \\
\hline $0-4$ & 1.00 & 1.00 & 1.00 & 1.00 & 1.00 & 1.00 \\
\hline $5-8$ & $1.40(0.93 ; 2.10)$ & $1.32(0.86 ; 2.02)$ & $1.09(0.79 ; 1.49)$ & $0.97(0.70 ; 1.34)$ & $1.09(0.73 ; 1.62)$ & $1.06(0.69 ; 1.62)$ \\
\hline $9-11$ & $1.29(0.77 ; 2.09)$ & $1.26(0.74 ; 2.15)$ & $1.21(0.84 ; 1.75)$ & $1.02(0.68 ; 1.53)$ & $1.51(0.98 ; 2.35)$ & $1.32(0.81 ; 2.15)$ \\
\hline$\geq 12$ & $1.29(0.70 ; 2.40)$ & $1.28(0.63 ; 2.62)$ & $1.22(0.76 ; 1.96)$ & $0.95(0.54 ; 1.66)$ & $1.50(0.86 ; 2.61)$ & $1.43(0.71 ; 2.86)$ \\
\hline Maternal BMI $\left(\mathrm{kg} / \mathrm{m}^{2}\right)$ & $p<0.001 * \star$ & $p<0.001 \star \star$ & $p<0.001 * \star$ & $p<0.001 * \star$ & $p<0.001 * \star$ & $p<0.001 * *$ \\
\hline$\leq 18.5$ & $4.68(2.21 ; 9.91)$ & $4.36(1.98 ; 9.60)$ & $0.89(0.20 ; 3.92)$ & $1.03(0.23 ; 4.63)$ & $1.02(0.13 ; 7.88)$ & $1.23(0.15 ; 9.77)$ \\
\hline $18.5-24.9$ & 1.00 & 1.00 & 1.00 & 1.00 & 1.00 & 1.00 \\
\hline $25.0-29.9$ & $0.36(0.24 ; 0.54)$ & $0.34(0.23 ; 0.52)$ & $1.35(0.99 ; 1.85)$ & $1.39(1.01 ; 1.92)$ & $1.90(1.24 ; 2.91)$ & $1.80(1.17 ; 2.78)$ \\
\hline$\geq 30.0$ & $0.39(0.23 ; 0.66)$ & $0.36(0.21 ; 0.61)$ & $2.46(1.77 ; 3.41)$ & $2.74(1.95 ; 3.84)$ & $4.65(3.06 ; 7.06)$ & $5.03(3.29 ; 7.67)$ \\
\hline
\end{tabular}

OR: odds ratio; $95 \% \mathrm{Cl}$ : 95\% confidence interval; BMI: body mass index.

* The "normal" group is the reference category for nutritional status;

** $\mathrm{p}$-value for linear trend.

out in Spain 23 with adolescent subjects aged 13 years showed that coming from a family of higher socioeconomic status was the major predictor of obesity. In the United States, an inverse association was found only among white female adolescents; among black adolescents of both sexes, this association was a direct one 24 . We detected a strong dose-response effect of the assets index on prevalence of overweight and obesity among boys. Among girls, overweight was more frequent only among the richest (5 $\left.5^{\text {th }}\right)$ quintile, whereas the odds ratio (OR) for obesity increased through to the $4^{\text {th }}$ quintile but then fell in the $5^{\text {th }}$. In other words, while excess weight shows a direct linear relationship with socioeconomic status among boys, among girls this association shows an inverted "J-shape." Similar trends have been reported in countries undergoing nutritional transition, in which higher prevalence of obesity is shifting towards adult women of lower socioeconomic status 25 .

Maternal schooling is expected to have a strong influence on nutritional status among children and adolescents, since the mother is usually responsible for determining a child's diet.
Among Pelotas adolescents, maternal schooling was inversely associated with thinness, but only among boys. Overweight and obesity were only positively associated with maternal schooling in crude analysis, an association which disappeared after adjustment for the assets index. Again, maternal schooling seems not to have an effect on nutritional status among girls in this age group. However, the study of Spanish adolescents mentioned previously 23 detected a positive association between maternal schooling and obesity. Based on these results, we speculate that prevention and treatment of overweight and obesity will require more than knowledge of its risk factors, which is also true for other conditions, such as smoking and physical inactivity. In addition to strong individual determination, fighting excess weight also depends on being in a conducive environment, which should combine favorable psychological and socioeconomic conditions, a good family support structure, adequate perception of body image, and knowledge of the present and future risks associated with excess weight, among other factors. 
Maternal BMI was the only variable to show a strong association - inverse in the case of thinness and direct in the case of overweight and obesity - with the outcomes among adolescents of both sexes, even after adjustment for skin color, schooling, and assets. Such associations may be explained by the joint influence of genetic and environmental factors. The dietary patterns and lifestyle of parents can influence their children's preferences and behavior. Other studies have also reported similar associations, reporting effects for paternal and maternal obesity simultaneously $26,27,28,29$; maternal obesity only $26,27,29$; or paternal obesity only $26,29,30$. A study by Cutting et al. 27 showed that heavier mothers have heavier daughters; failure to restrict the consumption of certain unhealthy foods in their own diet was associated with the child's weight, and daughters of mothers who were more liberal with respect to diet had greater access to any type of food. In the present study, obese mothers were five times more likely to have obese daughters; among boys, excess risk was threefold. We were unable to obtain anthropometric measurements of fathers in the present study, and were thus unable to measure the effect of paternal BMI on adolescent nutritional status. A study by Bralic et al. 26 with Croatian adolescents aged 11 years reported an association in the same direction. The finding that the nutritional status of the mother has a greater effect on that of her daughters than of her sons may indicate the presence of a strong behavioral component, which should be considered when planning future interventions. The recent identification of genes related specifically to excess weight 31 also confirms the existence of important genetic factors.

It is important to highlight the fact that we were unable to find studies that used the same criteria for nutritional evaluation used for the 1993 Pelotas birth cohort. For this reason, any comparisons of prevalences between this and other studies should be viewed with caution. On the other hand, comparisons with other studies did allow us to evaluate trends in the relationship between nutritional status and sex, socioeconomic level, and maternal schooling.

In summary, although prevalence of overweight and obesity was high, prevalence of thinness was still not negligible. Interventions should be implemented urgently in order to halt the increase in excess weight among children and adolescents. School is an ideal place for such initiatives, but acting at the family level will also be required, as shown by the important role played by maternal BMI. To this end, it will be essential that local and regional governments establish wide-ranging nutrition policies, capable of generating effective and immediate action aimed at deterring the obesity epidemic. 


\section{Resumo}

O objetivo deste estudo foi avaliar a influência de fatores demográficos, sócioeconômicos e maternos sobre o estado nutricional de adolescentes, nascidos em 1993, em Pelotas, Rio Grande do Sul, Brasil. A amostra estudada $(n=4.452)$ representa $87,5 \%$ da coorte original. $O$ estado nutricional foi avaliado conforme as recomendações da Organização Mundial da Saúde, categorizado em magro, eutrófico, sobrepeso e obeso. As variáveis independentes foram cor da pele, índice de bens, escolaridade e indice de massa corporal (IMC) maternos. As análises foram estratificadas por sexo, e a regressão logística multinomial foi usada. Ao todo, 7\% dos adolescentes eram magros, 11,6\% tinham sobrepeso e 11,6\% eram obesos. Entre os meninos, a prevalência de adolescentes magros apresentou associação inversa com escolaridade e IMC maternos. Entre as meninas, ser magra se associou inversamente com o IMC materno. Sobrepeso e obesidade mostraram-se associados diretamente com índice de bens e IMC maternos, sendo esta última, a principal variável associada com o estado nutricional dos adolescentes.

Estado Nutricional; Adolescente; Estudos de Coortes

\section{Contributors}

C. L. Araújo coordinated fieldwork and wrote the manuscript. S. C. Dumith performed the statistical analysis and participated in writing the manuscript. A. M. B. Menezes coordinated fieldwork and participated in writing the manuscript. P. C. Hallal coordinated fieldwork and participated in statistical analysis and in writing the manuscript. M. F. A. Vieira was responsible for nutritional analysis and participated in writing the manuscript S. W. Madruga carried out most of the literature review, and participated in data collection and in writing and revising the final version of the manuscript. C. G. Victora participated in writing and revising the final version of the article.

\section{Acknowledgments}

The cohort study is supported by the Wellcome Trust. The initial phases of the cohort study were funded by the European Union, the Brazilian National Program for Centers of Excellence (PRONEX), the National Research Council (CNPq), and the Brazilian Ministry of Health.

\section{References}

1. Behn A, Ur E. The obesity epidemic and its cardiovascular consequences. Curr Opin Cardiol 2006 21:353-60.

2. James WPT. The challenge of obesity and its associated chronic diseases. SCN News 2004; 29:39-43.

3. Kosti RI, Panagiotakos DB. The epidemic of obesity in children and adolescents in the world. Cent Eur J Public Health 2006; 14:151-9.

4. World Health Organization. Reducing risks, promoting health life. Geneva: World Health Organization; 2002

5. Galés-Camus C. Nutrition: an input and foundation for health. SCN News 2006; 32:6-9.

6. Uauy R, Solomons NW. The role of the international community: forging a common agenda in tackling the double burden of malnutrition. SCN News 2006; 32:24-37.
7. de Onis M, Blossner M. The World Health Organization Global Database on Child Growth and Malnutrition: methodology and applications. Int J Epidemiol 2003; 32:518-26.

8. Kelishadi R. Childhood overweight, obesity, and the metabolic syndrome in developing countries. Epidemiol Rev 2007; 29:62-76.

9. Wang Y, Monteiro C, Popkin BM. Trends of obesity and underweight in older children and adolescents in the United States, Brazil, China, and Russia. Am J Clin Nutr 2002; 75:971-7.

10. Kumanyika SK. Environmental influences on childhood obesity: ethnic and cultural influences in context. Physiol Behav 2008; 94:61-70.

11. Araújo CL, Menezes AMB, Vieira MFA, Neutzling MB, Gonçalves H, Anselmi L, et al. The 11-year follow-up of the 1993 Pelotas (Brazil) birth cohort: methods. Cad Saúde Pública 2010; 26: 1875-86. 
12. World Health Organization. Physical status: the use and interpretation of anthropometry. Report of a WHO Expert Committee. Geneva: World Health Organization; 1995. (Technical Report Series, 854).

13. Lohman TG, Roche AF, Martorell R. Anthropometric standardization reference manual. Champaign: Human Kinetics Books; 1988.

14. Cameron N. The measurement of human growth. Beckenham: Croom Helm Ltd.; 1984.

15. Kirkwood B, Sterne JAC. Essential medical statistics. 2nd Ed. Oxford: Blackwell Science Publishing; 2005.

16. Eveleth PB, Tanner JM. World variation in human growth. Cambridge: Cambridge University Press; 1990.

17. Black RE, Allen LH, Bhutta ZA, Caulfield LE, Onis M, Ezzati M, et al. Maternal and child undernutrition: global and regional exposures and health consequences. Lancet 2008; 371:243-60.

18. Ministério da Saúde. Pesquisa Nacional de Demografia e Saúde da Mulher e da Criança - PNDS 2008. Brasília: Ministério da Saúde; 2008.

19. Cordeiro LS, Lamstein S, Mahmud Z, Levinson FJ. Adolescent malnutrition in developing countries: a close look at the problem and at two national experiences. SCN News 2006; 31:6-13.

20. Ogden CL, Carroll MD, Curtin LR, McDowell MA, Tabak CJ, Flegal KM. Prevalence of overweight and obesity in the United States, 1999-2004. JAMA 2006; 295:1549-55.

21. Instituto Brasileiro de Geografia e Estatística. Pesquisa de Orçamento Familiar (POF) 2002-2003: antropometria e análise do estado nutricional de crianças e adolescentes no Brasil. Rio de Janeiro: Instituto Brasileiro de Geografia e Estatística; 2006.

22. Schneider D. International trends in adolescent nutrition. Soc Sci Med 2000; 51:955-67.
23. Serra-Majem L, Aranceta Bartrina J, Pérez-Rodrigo C, Ribas-Barba L, Delgado-Rubio A. Prevalence and deteminants of obesity in Spanish children and young people. Br J Nutr 2006; 96 Suppl 1: S67-72.

24. Wang Y, Zhang Q. Are American children and adolescents of low socioeconomic status at increased risk of obesity? Changes in the association between overweight and family income between 1971 and 2002. Am J Clin Nutr 2006; 84:707-16.

25. Gigante DP, Barros FC, Post CL, Olinto MTA. Prevalência de obesidade em adultos e seus fatores de risco. Rev Saúde Pública 1997; 31:236-46.

26. Bralic I, Vrdoljak J, Kovacic V. Associations between parental and child overweight and obesity. Coll Antropol 2005; 29:481-6.

27. Cutting TM, Fisher JO, Grimm-Thomas K, Birch LL. Like mother, like daughter: familial patterns of overweight are mediated by mothers' dietary disinhibition. Am J Clin Nutr 1999; 69:608-13.

28. Francis LA, Ventura AK, Marini M, Birch LL. Parent overweight predicts daughters' increase in BMI and disinhibited overeating from 5 to 13 years. Obesity (Silver Spring) 2007; 15:1544-53.

29. Hashimoto N, Kawasaki T, Kikuchi T, Takahashi H, Uchiyama M. Influence of parental obesity on the physical constitution of preschool children in Japan. Acta Paediatr Jpn 1995; 37:150-3.

30. Vogels N, Posthumus DL, Mariman EC, Bouwman F, Kester AD, Rump, et al. Determinants of overweight in a cohort of Dutch children. Am J Clin Nutr 2006; 84:717-24.

31. Frayling TM, Timpson NJ, Weedon MN, Zeggini E, Freathy RM, Lindgren CM, et al. A common variant in the FTO gene is associated with body mass index and predisposes to childhood and adult obesity. Science 2007; 316:889-94.

Submitted on 13/Feb/2009

Final version resubmitted on 30/Jul/2009

Approved on 11/Aug/2009 